\title{
Array Antennas of Size 8×8 Based on Hadamard Difference Sets
}

\author{
L. E. Kopilovich \\ A. Ya. Usikov Institute of Radio Physics and Electronics, NAS Ukraine, \\ 12, Acad. Proskura St., Kharkiv, 61085, Ukraine \\ E-mail:kopil@ire.kharkov.ua
}

Received March 13, 2008

The problem of synthesizing the optimized equi-amplitude array antenna (AA) on the $8 \times 8$ grid based on a Hadamard difference set is considered. By using newly found sets of this type on the $8 \times 8$ grid the 28- and 36-element AAs having a low sidelobe level are obtained.

A numerical experiment showed that by a small alteration of the structure of such a set, further reduction of the AA sidelobe radiation is possible.

\section{Introduction}

The idea of using cyclic difference sets (DSs) for synthesizing aperiodic linear array antennas (AAs) with a low sidelobe level (SLL) was suggested in [1], and it was generalized to the 2-D case in [2]. Further investigation of this issue in both linear and planar cases was described in monograph [3]. In particular, there it was shown that the basic DS class appropriate for the construction of planar aperiodic AAs is that of Hadamard difference sets ( $H$ sets [4]).

It will be mentioned that one can build the $H$ sets only on integer grids of definite sizes [5]. In each case there exist several inequivalent versions of such a set, where the number of the inequivalent $H$ sets has a tendency to grow with the larger grid size. Each of these sets generates an ensemble of equivalent $H$ sets, which can be obtained from the initial one by a definite procedure (see below); and after finding in each of the ensembles the set ensuring the minimum SLL for the AA, the best of them is then chosen.

The difficulty lies in the fact that now the complete collection of inequivalent $H$ sets is built only for the grids of sizes $4 \times 4,6 \times 6$, and $3 \times 12$; as for the grids of larger sizes, little is known in this respect.

In the recent paper [6] several new inequivalent $H$ sets on square $n \times n$ grids with $n=8,12,16$ and 24 were obtained, and the corresponding AAs having the minimized SLL were synthesized.
To further this line, the knowledge of new inequivalent $H$ sets is required.

This paper continues investigation of the AAs based on $H$ sets on the $8 \times 8$ grid. In this case, the number of the found inequivalent $H$ sets is brought up to twenty that enables obtaining an AA with improved characteristics. Also, a numerical experiment to clarify the possibility of further reducing of the AA SLL when the structure of the underlying $H$ set undergoes small alterations is carried out.

\section{General Information on $\boldsymbol{H}$ Sets}

By definition [7], a $k$-element DS $\left\{\left(a_{i}, b_{i}\right)\right\}$ on an integer $v_{x} \times v_{y_{-}}$grid is such a set that any nonzero node $(\bar{a}, \bar{b})$ of the grid has exactly $\Lambda$ representations of the form

$\bar{a} \equiv a_{i}-a_{j} \bmod v_{x}, \quad \bar{b} \equiv b_{i}-b_{j} \bmod v_{y}$,

where

$\Lambda=k(k-1) /(V-1), \quad V=v_{x} \cdot v_{y}$.

An $H$ set is a DS whose parameters satisfy the additial condition [8]

$V=4(k-\Lambda)$. 
$H$ sets exist on grids with [5]

$v_{x}=2^{n}, 3 \cdot 2^{n}, \quad v_{y}=v_{x}, \quad n \geq 1$,

and

$v_{x}=2^{n+1}, 3 \cdot 2^{n+1}, \quad v_{y}=v_{x} / 4, \quad n \geq 1$.

(An $H$ set on the $s \times t$ grid is equivalent to a perfect binary array PBA $(s \times t)$ [9] which represents a binary array of size $s \times t$ whose autocorrelation function remains constant with all cyclic shifts of its elements along the both grid sides [10]. Further, we make no distinction between an $H$ set and the corresponding PBA.)

It follows from (1)-(3) that the element number of an $H$ set is determined by parameter $V$ :

$$
k=\sqrt{V}(\sqrt{V} \pm 1) / 2 .
$$

Note that with the "-" in (4) the fill factor of the array $\beta=k / V<0.5$. The $H$ set for which one "+" is taken in (4) is called complementary. Its elements are placed in all grid nodes empty from those of the first set, so its element number is $k_{1}=v-k$.

For a square grid, $v_{x}=v_{y}=v$, and $k=v(v \pm 1) / 2$. Thus, $H$ sets with 28 and 36 elements can be build on the $8 \times 8$ grid.

It is known [7] that if there exists a DS with given parameters, then there also exists an ensemble of equivalent sets having the same parameter values; in the 2-D case, these sets are obtained from the initial one by a simultaneous cyclic shifting all its elements along the grid sides, and also by the grid automorphisms transforming it by the formulas

$a_{i 1}=c_{11} \cdot a_{i}+c_{12} \cdot b_{i}, \quad b_{i 1}=c_{21} \cdot a_{i}+c_{22} \cdot b_{i}$,

with $c_{11}, c_{12}, c_{21}, c_{22}$ integers $\left(a_{i 1}, b_{i 1}\right.$ are then taken modulo $v_{x}$, modulo $v_{y}$, respectively), provided the determinant of the equation system (5)

Det $=c_{11} \cdot c_{22}-c_{21} \cdot c_{12}$ is a number co-prime with the grid sidelengths [11].

In all known cases the 2-D $H$ sets exist in a number of inequivalent versions unobtainable one from another by the described procedure. Each of such sets possesses its own ensemble of the equivalent ones, so the total number of $H$ sets with given parameters is proportional to that of the inequivalent sets.

\section{New Inequivalent $H$ Sets on the $8 \times 8$ Grid}

For the $8 \times 8$ grid, two inequivalent $H$ sets are given in [12] and [13], and three more - in [6]. To our knowledge, no more inequivalent $H$ sets are given in the literature.

Here, we found 15 new inequivalent $H$ sets. Several such sets are obtained by using the formula [14]

$$
w_{2 i+r, j}=u_{i, 2 j+r},
$$

where $0 \leq i \leq s, 0 \leq j<t, 0 \leq r \leq 1, U=\left(u_{i j}\right)$ is a PBA of size $s \times(2 t)$, and $W=\left(w_{i j}\right)$ is an array of size $(2 s) \times t$. Under specific conditions, $W$ is also a PBA. The fulfilment of these conditions is difficult to check, however, one can make sure by direct verification that in our case (at $s=4, t=8$ ), $W$ is an $H$ set on the $8 \times 8$ grid. This allows to obtain $H$ sets on this grid by using the known $H$ sets on the $4 \times 16$ grid, and choose the inequivalent ones among them. As a main source for obtaining $H$ sets on the $8 \times 8$ grid by this method a wealth of $H$ sets on the $4 \times 16$ grid given in [15] was used; so, 8 new inequivalent $H$ sets were found. Besides, one such set was obtained from [12] in this way.

One more method consists in transforming an $H$ set $\left\{\left(a_{i}, b_{i}\right)\right\}$ into the set $\left\{\left(a_{i 1}, b_{i 1}\right)\right\}$ on the grid of the same size following the rule: if sum $a_{i}+b_{i}$ is an even number then $a_{i 1}=a_{i}, b_{i 1}=b_{i}$, whereas in the opposite case its odd component decreases by 1 and its even component increases by 1 (thus, in all cases, $a_{i 1}+b_{i 1}=a_{i}+b_{i}$ ). As the result, an $H$ set is again obtained, and among the sets obtained in such a way 6 new inequivalent ones occured. 
The found collection of the inequivalent $H$ sets is probably still incomplete, however, by using these sets the AAs having lower SLL than those obtained earlier were synthesized.

\section{Searching Procedure for the AA with Minimized SLL}

The normalized power pattern of a planar equiamplitude AA is

$$
F\left(q_{x}, q_{y}\right)=\left|\frac{1}{k} \sum_{j=1}^{k} \exp \left[i\left(a_{j} \cdot q_{x}+b_{j} \cdot q_{y}\right)\right]\right|^{2},
$$

where $a_{j}, b_{j}$ are now co-ordinates of an array element, $q_{x}$ and $q_{y}$ are the generalized space coordinates: $q_{x}=2 \pi d\left(l-l_{0}\right) / \lambda, q_{y}=2 \pi d\left(m-m_{0}\right) / \lambda$; $d$ is the distance between the adjacent nodes in an array row or column; $\lambda$ is the wavelength; $l, m$ are the cosines of the angles between the beam and the axes $x$ and $y$; and $\left(l_{0}, m_{0}\right)$ is the direction towards which the beam is pointed. In what follows, pattern (6) is optimized on the domain $\left(-\pi \leq q_{x} \leq \pi, \quad 0 \leq q_{y} \leq \pi\right)$, therefore, the results obtained are valid for any values of $d / \lambda$ and $l_{0}$, $m_{0}$; without losing generality, one can take $d=\lambda / 2$ and $l_{0}=m_{0}=0$.

When set $\left\{\left(a_{j}, b_{j}\right)\right\}$ represents a DS, function (6) takes the constant value $F_{c}=(k-\lambda) / k^{2}$ over the net of space points $\{(2 \pi s / v, 2 \pi t / v)\}$, $s+t \geq 0$ [4]. Therefore, we may expect that for a square AA, $F$ takes its maximum value near a point of the net

$$
\{(s \pi / v, t \pi / v)\} ; \quad s=-(v-1), \ldots,-1,0,1, \ldots, v-1 ;
$$

under the conditions

$$
\operatorname{Abs}(s)>2 \text { or } t>2 ;(s \cdot t) \bmod 4>0
$$

first of which means that only the sidelobe region is considered, and the second one - that the points at which $F=F_{c}$ are excluded.
The calculation was described in [6]; briefly, it is as follows. An $H$ set for which the quantity $F m=\max F(\mathrm{~dB})$ over the space points net (7) does not exceed some given $M$ is found; then the value of $\mathrm{Fm}$ over the net of double thickness is found, and so on. The process of double thickening continues until the magnitude of $\mathrm{Fm}$ is stabilized, coming to a certain quantity $F_{0}$.

Further, an $H$ set giving a value of $F m$ over net (7), (8) which is less than that for the initial set is searched for, and the described procedure giving now a new value of $F_{0}$ is repeated; if this value is smaller than the preceding one, such set is stored, and so on.

Note that a smaller value of $\mathrm{Fm}$ does not inevitably lead to a smaller value of $F_{0}$; therefore, to diminish the probability of omitting the real minimum value of the latter over the whole considered ensemble of $H$ sets, the described process was periodically repeated, beginning in each case from a new $H$ set of the ensemble.

The calculation was carried out through the ensembles corresponding to all known inequivalent $H$ sets on the $8 \times 8$ grid. As the result, the 28-element AA having the SLL $-12.59 \mathrm{~dB}$, and the 36-element AA with the SLL $-13.86 \mathrm{~dB}$ were synthesized. The power patterns of these AAs, together with the schemes of their element arrangement are given in Figs. 1 and 2.

\section{On the Possibility of Further SLL Reduction}

Recently, the so called genetic algorithms were applied to the synthesis of linear AAs in a number of papers, including those where cyclic DSs as initial ones were taken [16]. In some cases, one can pass from a linear grid to a rectangular one having coprime sidelengths, thus obtaining a planar AA.

In this way, it is impossible to obtain a square AA. However, in this case one can search for an AA with a still smaller SLL by slightly altering the underlying $H$ set, e. g., by shifting a few of its elements from their places to other grid nodes, and then calculating through the ensemble of sets obtainable from such a set by the same described procedure. 


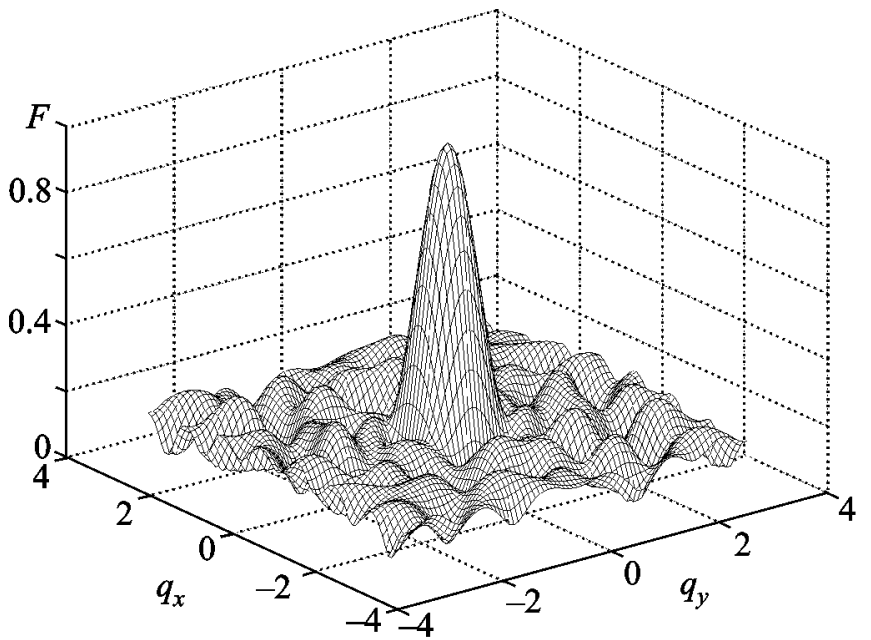

a)

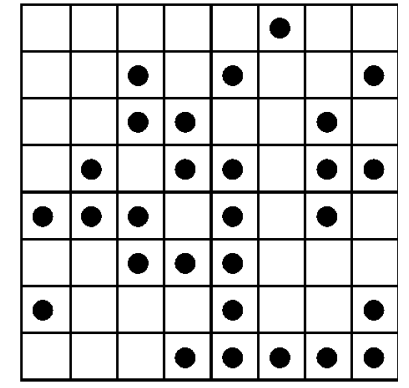

b)

Fig. 1. The power pattern of the optimized 28-element $A A(a)$, and the scheme of its element arrangement (b)

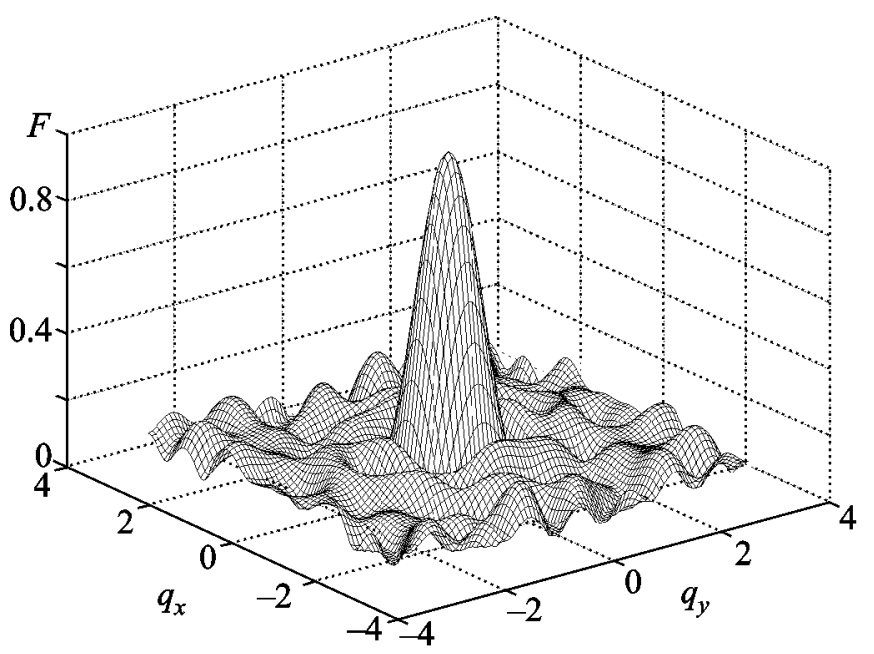

a)

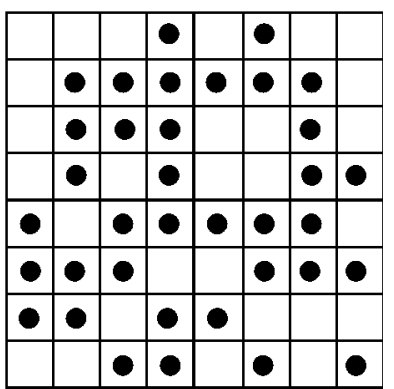

b)

Fig. 2. The power pattern of the optimized 36-element $A A(a)$, and the scheme of its element arrangement (b)

We made a numerical experiment using inequivalent $H$ sets having a structure of the form shown in Fig. 3. Here, in three rows of the grid there are two set elements, six elements in one row and four elements in each of the rest rows. While making by turns all possible element shifting in the rows containing only two elements of the set, one obtains, in each case, a "disturbed" $H$ set, and when taking this set and that complementary to it as the initial ones, we obtain, by using the aforesaid procedure, the ensembles of 28- and 36-element sets.

The calculation through these set ensembles has shown that in this way the AAs with smaller SLLs can be synthesized. As an example, a "disturbed” 36-element set ensuring the SLL -14.43 $\mathrm{dB}$ is shown in Fig. 4. 


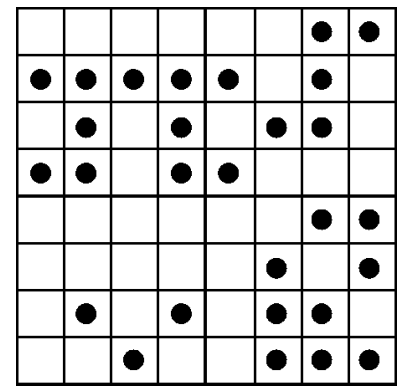

Fig. 3. The scheme of the element arrangement in the $H$ sets used in the numerical experiment

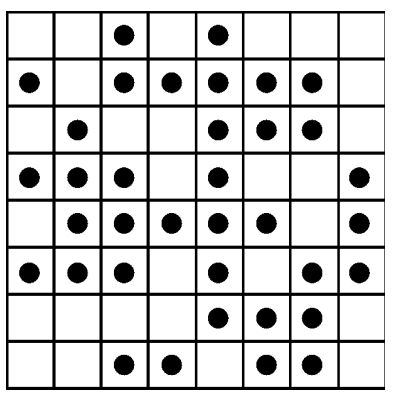

Fig. 4. The 36-element "disturbed" $H$ set ensuring the reduced $S L L$ of $-14.43 \mathrm{~dB}$

\section{Conclusion}

The collection of the inequivalent $H$ sets found also allows obtaining optimized AAs of larger sizes. Thus, by the method suggested in [14, 15] and somewhat simplified in [3], when having an $H$ set on the $s \times t$ grid, one can obtain the $H$ set on the $(2 s) \times(2 t)$ grid. In this way the $H$ sets on the $16 \times 16$ grid can be built, and on their base the AAs with a large number (120 and 136) of elements having a low SLL synthesized, that becomes pressing in the development of modern radio telescopes [17].

\section{References}

1. D. G. Leeper, “Thinned periodic antenna arrays with improved peak sidelobe level control”, U.S. Patent 4071848, Jan. 31, 1978.
2. L. E. Kopilovich and L. G. Sodin, "Two-dimensional aperiodic antenna arrays with a low sidelobe level”, IEE Proc., pt. H, vol. 138, No.3, pp. 233-237, 1991.

3. L. E. Kopilovich and L. G. Sodin, Multielement System Design in Astronomy and Radio Science. Dordrecht/Boston/ London: Kluwer Academic Publishers, Astrophysics and Space Science Library, vol. 268, 2001, 190 p.

4. R. J. Turyn, "Character sums and difference sets", Pacific J. Math., vol. 15, No.1, pp. 319-346, 1965.

5. P. Wild, "Infinite families of perfect binary arrays", Electron. Lett., vol. 24, No.14, pp. 845-847, 1988.

6. L. E. Kopilovich, "Square array antennas based on Hadamard difference sets”, IEEE Trans. Antennas Propag., vol. AP-56, pp. 263-266, Jan. 2008.

7. M. Hall Jun., Combinatorial Theory, 2nd ed, New York: Wiley, 1986.

8. P. K. Menon, “On difference sets whose parameters satisfy a certain relation”, Proc. Am. Math. Soc., vol. 13, No.5, pp. 739-745, 1962.

9. Y. K. Chan, M. K. Siu and P. Tong, “Two-dimensional binary arrays with good autocorrelation”, Information and Control, vol. 42, pp. 125-130, 1979.

10. D. Calabro and J. K. Wolf, “On the synthesis of two-dimensional arrays with desirable correlation properties”, Information and Control, vol. 11, pp. 537-560, 1968.

11. A. G. Kurosh, Theory of Groups, New York: Chelsea, 1958.

12. D. Jungnickel and A. Pott, “Abelian difference sets”, in The CRC Handbook of Combinatorial Designs, Ch. D. Colbourn and J. H. Dinitz, Eds. Roca Baton: CRC Press, 1996, pp. 15-64.

13. L. Bömer and M. Antweiler, "Two-dimensional perfect binary arrays with 64 elements”, IEEE Trans. Inf. Theory, vol. IT-36, No.2, pp. 411-414, 1990.

14. J. Jedwab and C. Mitchell, "Constructing new perfect binary arrays”, Electron. Lett, vol. 24, No.11, pp. 650-652, 1988.

15. K. T. Arasu and J. Reis, “On Abelian group of order 64 that have difference sets”. Tech. Rept, No. 1987.10, Dept of Math. and Stat. of Wright State University, Dayton, 1987, 12 p.

16. S. Caorsi, A. Lommi, A. Massa and M. Pastorino, "Peak sidelobe level reduction with a hybrid approach based on GAs and difference sets”, IEEE Trans. Antennas Propag., vol. 52, pp. 1116-1121, Apr. 2004.

17. L. Kogan, “Optimizing a large array configuration to minimize the sidelobes”, IEEE Trans. Antennas Propag, vol. 48, pp. 1075-1078, July 2000. 


\section{Антенные решетки размера $8 \times 8$ на основе адамаровских разностных множеств}

\section{Л. Е. Копилович}

Рассматривается вопрос синтеза антенных решеток (АР) на основе адамаровских разностных множеств. С использованием новых найденных множеств этого типа на решетке $8 \times 8$ получены 28- и 36-элементные АР с низким уровнем боковых лепестков.

Численный эксперимент показал, что путем небольших изменений структуры таких множеств можно добиться дальнейшего снижения уровня бокового излучения.

\section{Антенні решітки розміру $8 \times 8$ на базі адамаровських різницевих множин}

\section{Л. Ю. Копилович}

Розглядається питання щодо синтезу антенних решіток (АР) на базі адамаровських різницевих множин. 3 використанням нових знайдених множин цього типу на решітці $8 \times 8$ отримані 28- та 36-елементні АР з низьким рівнем бокових пелюстків.

Числовий експеримент показав, що шляхом незначних змін у структурі таких множин можна домогтися подальшого зниження рівня бокового випромінювання. 